\title{
Crystal Structures of the $\mathrm{RCo}_{5}$ and $\mathrm{R}_{2} \mathrm{Co}_{17}$ Types Observed in Polystyrene Latexes*
}

\author{
By Masayuki Hasaka**, Hiromichi Nakashima** and Kensuke Oki***
}

\begin{abstract}
Polystyrene latexes with particles of diameters 250 and $500 \mathrm{~nm}$ are observed under a metallurgical microscope. The crystal structures of the $\mathrm{RCO}_{5}$ and the $\mathrm{R}_{2} \mathrm{Co}_{17}$ types appear stably through the thermal motion of particles, where $R$ means rare earth element. Various defects such as diffuse interfaces, dislocations, point defects, amorphous structures, or segregations of the large and the small particles are distinctly observed in these structures. Polystyrene latexes are found to be useful to study on an atomic scale the crystal structures and their kinetic behavior of intermetallic compounds of the R-Co system.
\end{abstract}

(Received July 2, 1983)

Keyzords: latex, polystyrene latex, $\mathrm{RCo}_{5}, \mathrm{R}_{2} \mathrm{Co}_{17}$, intermetallic compound

\section{Introduction}

An aqueous suspension of polystyrene particles is called "polystyrene latex". The particles in the latex disperse stably under an electrical interaction and an external pressure ${ }^{(1)-(8)}$. In the dense latex the particles move thermally to form crystal structures, as if they behaved like atoms in metals and alloys. According to recent papers, the latex is undistinguishable from the real metallic crystal in many aspects such as the plastic deformation mechanism, the melting mechanism, the dynamical properties of the crystalline state and the atomic behavior of the liquid state ${ }^{(9)(10)}$. Furthermore, the type of the crystal structure in the latex depends on a particle diameter ratio $\gamma$ of the large and the small particles: the $\mathrm{NaZn}_{13}$, the $\mathrm{AuCu}$ (?) or the $\mathrm{AlB}_{2}$ type appears for the case of $\gamma=$ 2.04; the $\mathrm{CaCu}_{5}$ type, namely, the $\mathrm{RCo}_{5}$ type for $\gamma=1.77$, where $\mathbf{R}$ means the rare earth element ${ }^{(11)(12)}$; the $\mathrm{MgCu}_{2}$ or the $\mathrm{MgZn}_{2}$ type of the Laves phase for $\gamma=1.4$ to $1.7^{(13)(14)}$. Thus the latex is an interesting object for metal$\operatorname{lurgy}{ }^{(15)-(18)}$ as well as physics, chemistry, and

* This paper was originally published in Japanese in J. Japan Inst. Metals, 46 (1982), 16.

** Department of Materials Science and Engineering, Faculty of Engineering, NagasakiUniversity, Nagasaki 852, Japan.

*** Department of Materials Science and Technology, Graduate School of Engineering Sciences, Kyushu University, Kasuga 816, Japan. biology ${ }^{(6)}$. It is, therefore, promising that the observation of the latex gives some clue for solving the involved problems about atomic arrangements and their changes in metals and alloys.

In the present paper, under a metallurgical microscope the authors have found the structure of the $\mathrm{R}_{2} \mathrm{Co}_{17}$ type in addition to the structures of the $\mathrm{RCO}_{5}$ type in the latexes with the particles of diameters 250 and $500 \mathrm{~nm}$, and have obtained much information about the crystallization process and the lattice defects of these structures.

\section{Method for Preparation and Observation of Polystyrene Latexes}

The polystyrene latexes with particles of diameters 250 and $500 \mathrm{~nm}$ were prepared by emulsion polymerization ${ }^{(4)}$ at $350 \mathrm{~K}$, using ionexchanged water $240 \mathrm{~cm}^{3}$, styrene $100 \mathrm{~cm}^{3}$, sodium carbonate $0.13 \mathrm{~g}$, sodium dodecyle sulfate (SDS) 0.30 or $0.13 \mathrm{~g}$, and potassium persulfate $0.13 \mathrm{~g}$ disolved in ion-exchanged water $60 \mathrm{~cm}^{3}$. The particle diameters scatter below $5 \mathrm{~nm}$ for the small particles prepared with SDS $0.3 \mathrm{~g}$ and $10 \mathrm{~nm}$ for the large ones prepared with SDS $0.13 \mathrm{~g}$. After these latexes were diluted $2 / 5$ times with ion-exchanged water, they were deionized by ion-exchanged resin Amberlite MB3 and were mixed in the observation cell by the same method as described previously(13)(14). The large and the small particles in the mixed latexes were three- 
dimensionally observed by shifting the focus under a metallurgical microscope of inverted type by the oil immersion method. The alphabetical order of $a, b$, and $c$ in the following figures signifies that each focus slightly shifted into the inner side of the latexes in the observation cell.

\section{Results of Observation and Discussion}

Figure 1 shows how the particles of diameters 250 and $500 \mathrm{~nm}$ in the polystyrene latexes are situated as if they were atoms in the liquid or the amorphous state. The large and the small particles form no crystals with long-range order, but align three-dimensionally and orderly in the narrow region near the center of the figure. Such local regions appear repeatedly and disappear time after time at the early stage, and then they grow slowly through the thermal motion of the particles.

Figure 2 shows the particle arrangement at the later stage, which appeared at $385 \mathrm{ks}$
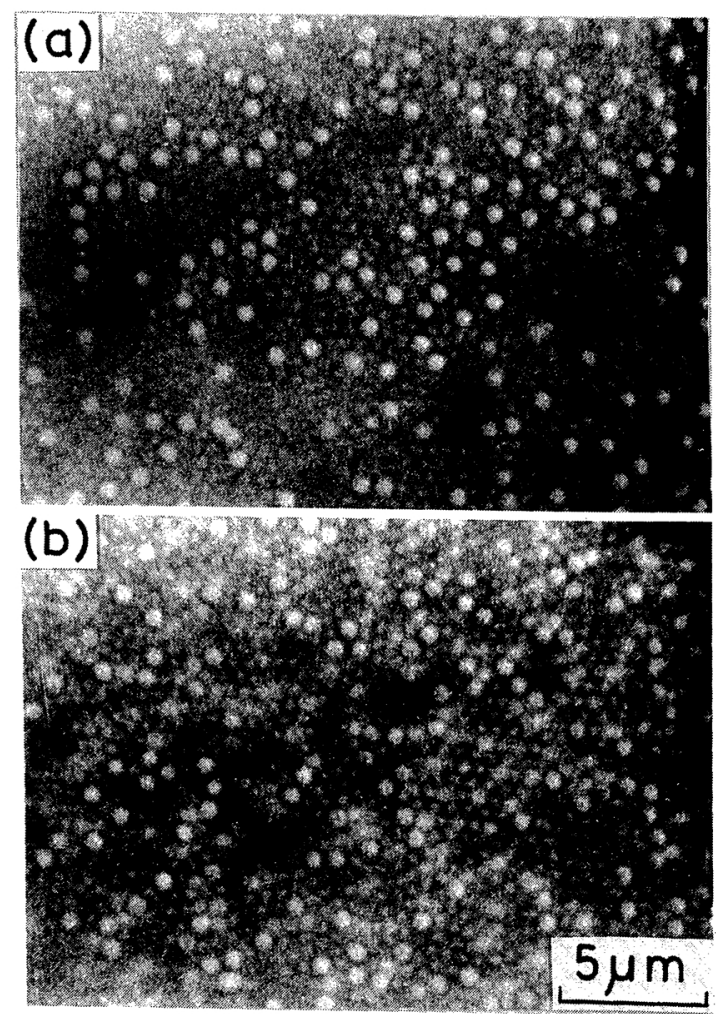

Fig. 1 Nucleation of crystals in polystyrene latexes.
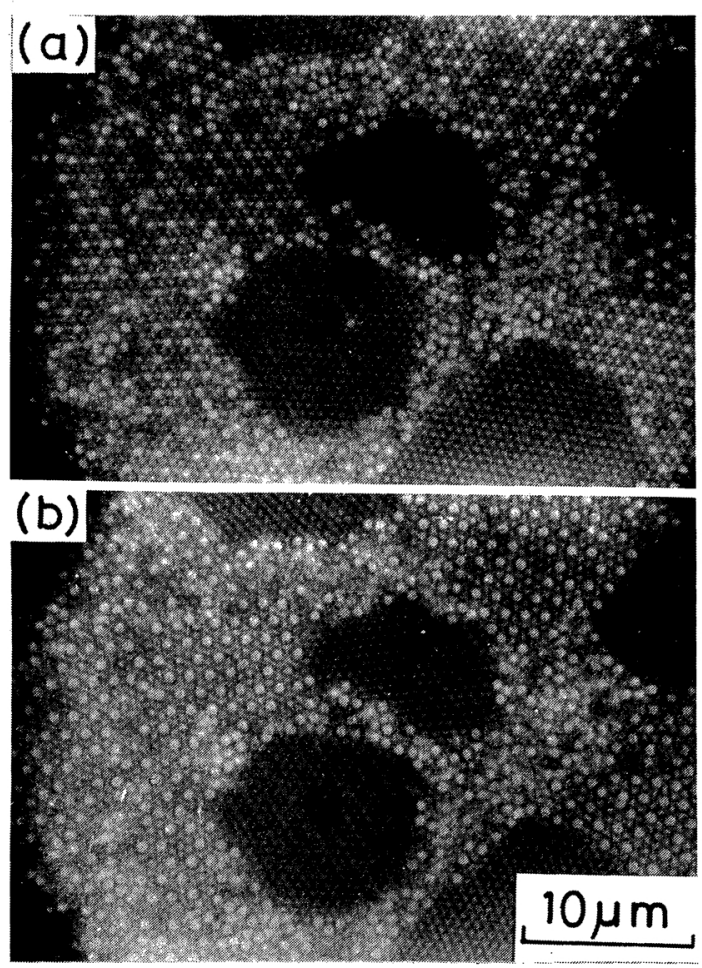

Fig. 2 Later stage of crystallization in polystyrene latexes.

$(107 \mathrm{~h})$ after pouring the two latexes into the test tube. While the liquid or the amorphous state is vanishing, the particles are orderly aligning in the wide region. Because the large and the small particles disperse inhomogeneously, the ordered arrangements of the particles are seen in the two regions formed with different ingredients, i.e. only the small particles and both the large and the small particles.

Figure 3 shows the particle arrangement at $47 \mathrm{ks}(13 \mathrm{~h})$ after taking Fig. 2. The particles align orderly throughout the visual field. The ordered region formed with both the large and the small particles becomes wider, whereas the region formed with the small particles becomes narrower. If the large particles are considered to correspond to $\mathrm{R}$ and the small particles to $\mathrm{Co}$, the large and the small particles in this widely ordered region reproduce the structure of the $\mathrm{RCo}_{5}$ type of the intermetallic compound which is illustrated in Fig. $4^{(19)-(21)}$. Namely the observed particles are situated at the positions of the white spheres in Fig. 4(a) for Fig. 

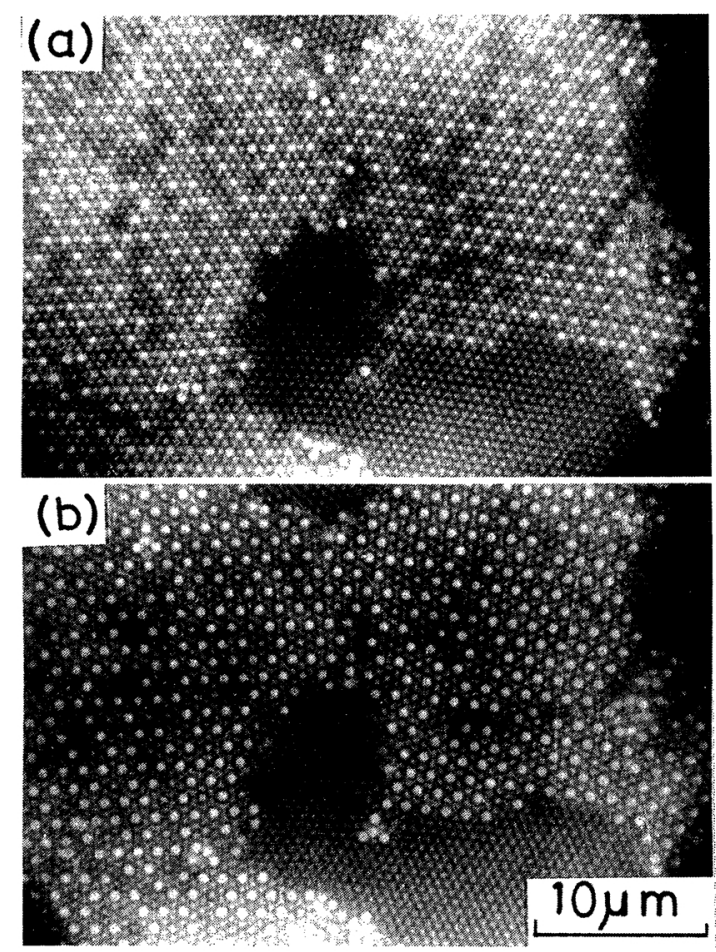

Fig. 3 Structures of the $\mathrm{RCo}_{5}$ and Co types. Small particles correspond to Co and large particles to $\mathbf{R}$. Lattice defects can be seen.

3(a) and in Fig. 4(b) for Fig. 3(b); because of the different focus of microscope, the particles in Fig. 3(a) correspond to $R$ in the $\{R \cdot 2 \mathrm{Co}\}$ plane and $\mathrm{Co}$ in the $\{3 \mathrm{Co}\}$ plane, while the particles in Fig. $3(\mathrm{~b})$ correspond to $\mathrm{R}$ and $\mathrm{Co}$ in the $\{\mathrm{R} \cdot 2 \mathrm{Co}\}$ plane. On the other hand, the small particles in the narrow region form the structure of the pure Co metal. In both figures, some lattice defects can be seen. Dislocations exist around the interface between the structures of the $\mathrm{RCo}_{5}$ type and the Co metal. The large and the small particles in the structure of the $\mathrm{RCo}_{5}$ type interchange wrongly their positions here and there. The small particles segregate along the boundary across which the upper crystal is displaced from the lower crystal by $\vec{R}=(a / 2)\langle 100\rangle$, as is seen on the right side of Fig. 3(a) or (b).

Generally the structure of the $\mathrm{RCo}_{5}$ type is formed, if the atomic diameter ratio of $\mathrm{R}$ to $\mathrm{Co}$ is about $1.5^{(22)}$. The particle diameter ratio $\gamma=2.00$ used in this work can not explain the formation of the structure for the $\mathrm{RCo}_{5}$ type in
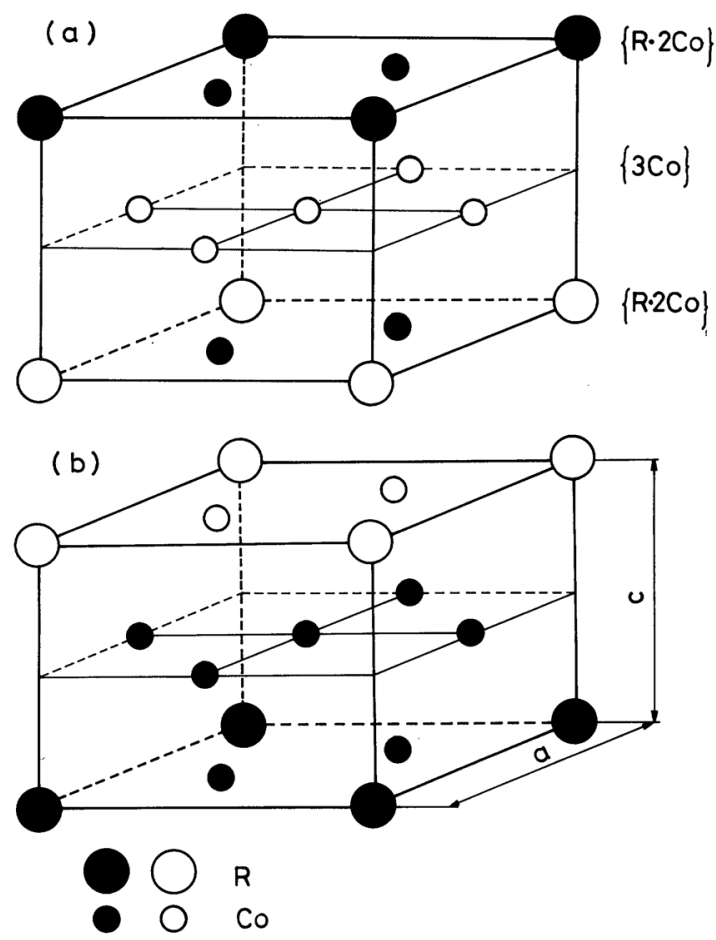

Fig. 4 Stacking scheme in the structure of the $\mathrm{RCO}_{5}$ type. White spheres in the figures (a) and (b) show the particles observed in Fig. 3(a) and (b), respectively.

the latexes. It should be noted, however, that the effective particle diameter $d_{\text {eff }}$ is larger than the real particle diameter because each particle has an electrical double layer around itself ${ }^{(12)}$. If we assume $d_{\text {eff }}$ as the interparticle spacing, $d_{\text {eff }}$ for the small particles is estimated as $580 \mathrm{~nm}$ from Fig. 3 by measuring with a magnifier, being $330 \mathrm{~nm}$ larger than the real particle diameter $250 \mathrm{~nm}$. Though $d_{\text {eff }}$ for the large particles can not be estimated by the same method from Fig. 3, it is assumed to be also $330 \mathrm{~nm}$ larger than the particle diameter $500 \mathrm{~nm}$, being estimated as $830 \mathrm{~nm}$. Thus the effective particle diameter ratio is about 1.43 , which explains well the experimental fact that the structure of the $\mathrm{RCo}_{5}$ type appears in the present latexes with $\gamma=2.00$. The effective particle diameter ratio is in turn very close to the atomic diameter ratio of $\mathrm{Sm}$ to Co $1.44^{(23)}$. It is suggested from this work and other ones ${ }^{(11)-(14)}$ that the structure of the $\mathrm{RCo}_{5}$ type appears in the latex with $\gamma=$ about 1.77 to 




Fig. 5 Segregation of small particles in the boundary which can be described by a displacement $(a / 2)\langle 110\rangle$, normal to the boundary.

\subsection{0 .}

Figures 5 and 6 show the segregations of the particles around boundaries in the structure of the $\mathrm{RCo}_{5}$ type. As is seen in Fig. 5, the small particles segregate to fill the gap of the boundary across which the upper and the lower crystals are displaced by $\vec{R}=(a / 2)\langle 110\rangle$ from each other, normally to the boundary. On the other hand, Fig. 6 shows that the large particles segregate remarkably at the $30^{\circ}$-tilt boundary in the $\{3 \mathrm{Co}\}$ plane, that is, the plane formed with only the small particles. The segregations of the large and the small particles result in offstoichiometry from the ratio of 1:5 and exhibit the morphology of the various boundaries.

Figure 7 shows the particle arrangement which corresponds to the $\{001\}$ structure of the $\mathrm{R}_{2} \mathrm{Co}_{17}$ type. Such a structure is produced, when a pair of $\mathrm{Co}$ is orderly replaced at the position of one $R$ per three $\mathrm{RCo}_{2}$ in the $\{R$. $2 \mathrm{Co}$ plane, as is illustrated in Fig. 8 . In the
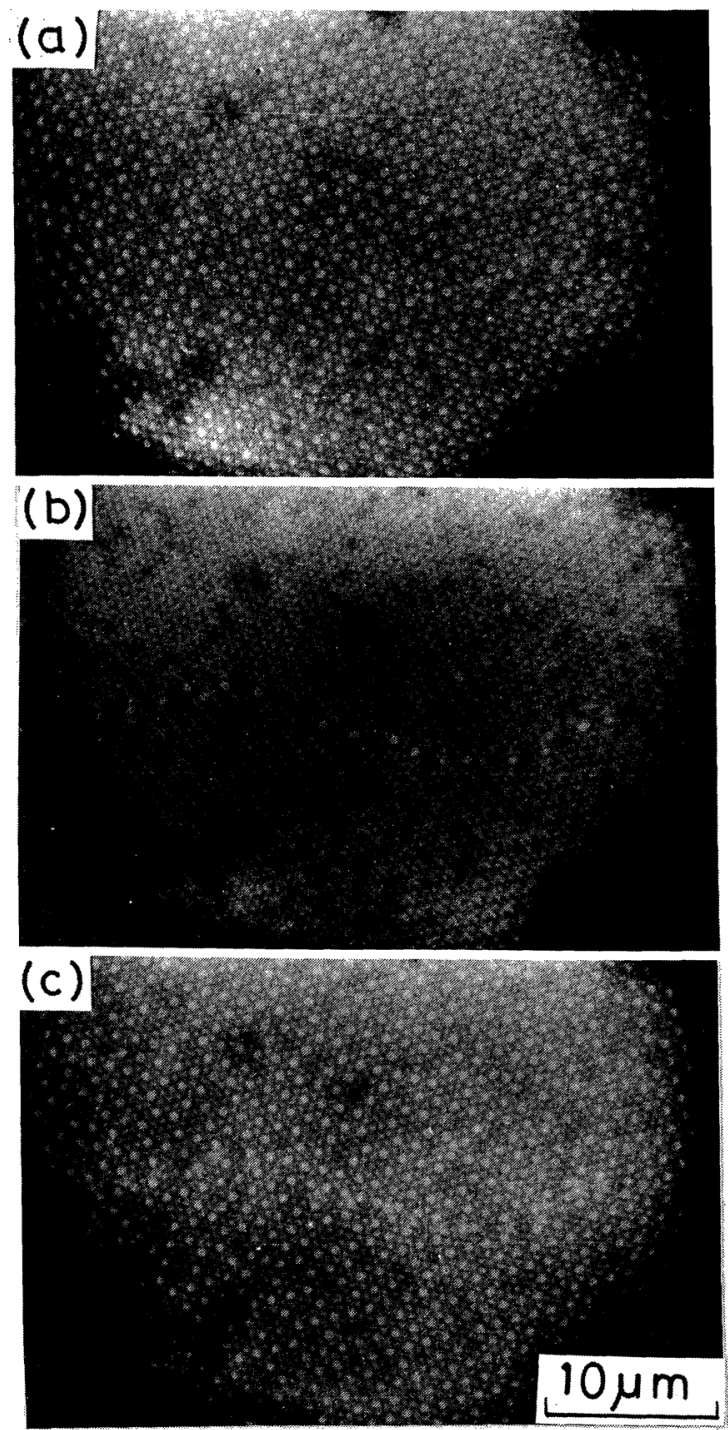

Fig. 6 Segregation of large particles in the $30^{\circ}$-tilt grain boundary.

photograph hexagonal stitches of the large particles are locally combined, and the structure of the $\mathrm{RCo}_{5}$ type appears locally. Because both structures of the $\mathrm{RCo}_{5}$ and the $\mathrm{R}_{2} \mathrm{Co}_{17}$ types appear in the latexes as well as in the real intermetallic compounds of the R-Co system, the latex is conspicuous as the model on an atomic scale for the real intermetallic compounds of the R-Co system.

The black spots in Fig. 9 correspond to the lattice positions, where Co is situated instead of $R$ in the $\{R \cdot 2 \mathrm{Co}\}$ plane. These few positions 


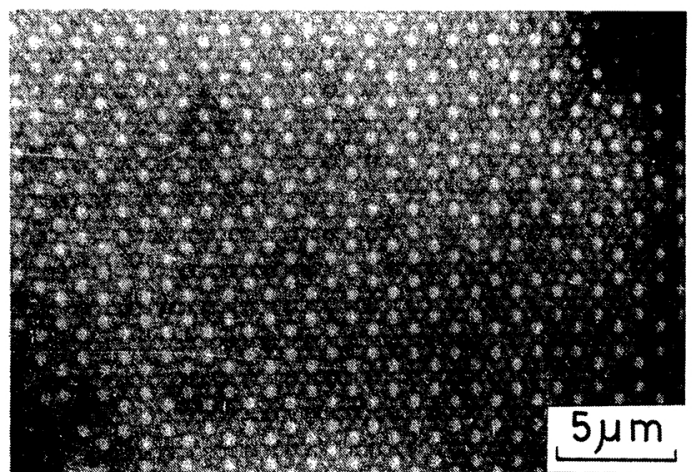

Fig. 7 A $\{001\}$ plane in the structure of the $\mathrm{R}_{2} \mathrm{Co}_{17}$ type. Hexagonal stitches of large particles are partially broken.

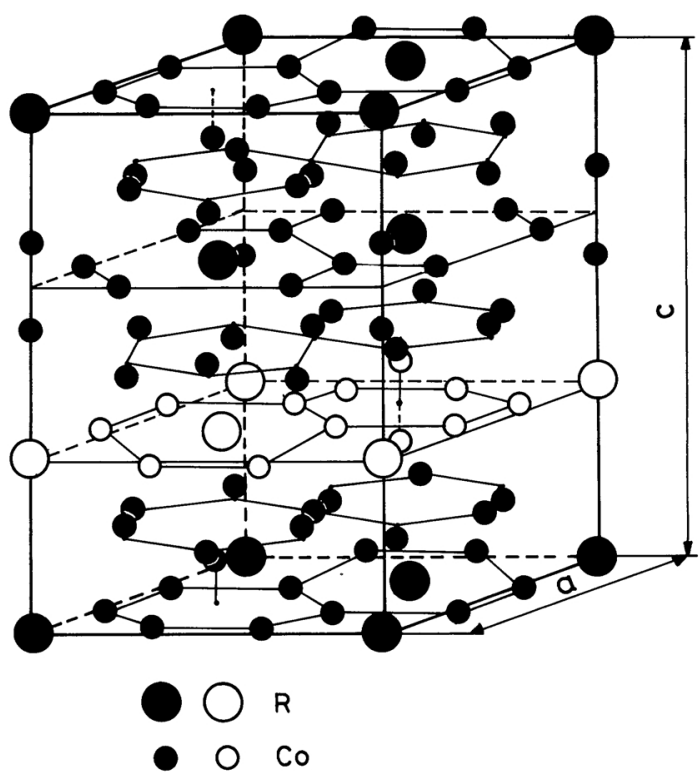

Fig. 8 Unit cell of the structure of the $\mathrm{R}_{2} \mathrm{Co}_{17}$ type. White spheres show particles observed in Fig. 7.

are distributed randomly on the right side of the figure, while these many positions of black spots align orderly when we look on the left side of the figure. The structure of the $\mathrm{RCo}_{5}$ type seems to change gradually to the structure of the $\mathrm{R}_{2} \mathrm{Co}_{17}$ type with turning to the left side from the right side. The diffused interface between both structures in the figure suggests distinctly that the structures of the $\mathrm{RCo}_{5}$ and the $\mathrm{R}_{2} \mathrm{Co}_{17}$ types may spinodally separate as was indicated by Mishra and Thomas ${ }^{(24)}$.

Figures 10 and 11 show the ordered arrangements of the large and the small particles which

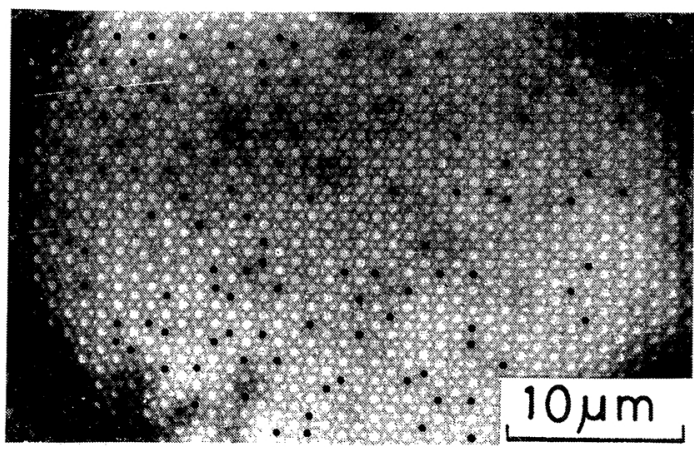

Fig. 9 Transformation of the structures from the $\mathrm{RCO}_{5}$ type to the $\mathrm{R}_{2} \mathrm{Co}_{17}$ type. Interface between two phases is diffused like a spinodal interface.

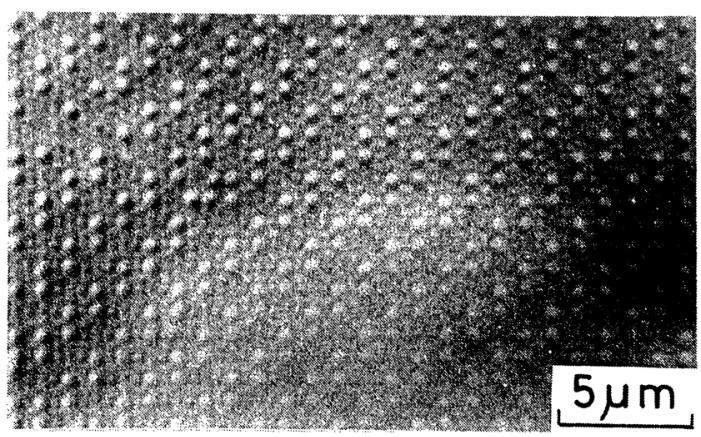

Fig. 10 A $\{110\}$ plane in the structure of the $\mathbf{R}_{2} \mathrm{Co}_{17}$ type. Lattice parameter: $a=1.7 \mu \mathrm{m}, c=2.5 \mu \mathrm{m}$.

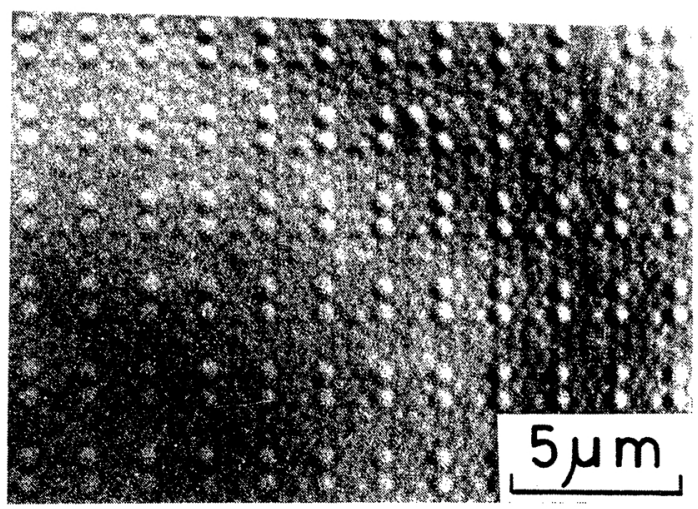

Fig. 11 A $\{100\}$ plane in the structure of the $\mathbf{R}_{2} \mathbf{C o}_{17}$ type. Lattice parameter: $a=1.9 \mu \mathrm{m}, c=2.8 \mu \mathrm{m}$.

are frequently observed. These arrangements correspond to the $\{110\}$ and $\{100\}$ structures of the $\mathrm{R}_{2} \mathrm{Co}_{17}$ type, as illustrated in Figs. 12 and $13^{(19)(20)}$. The photographs reproduce the real complicated structure of the $\mathrm{R}_{2} \mathrm{Co}_{17}$ type, where a pair of $\mathrm{Co}$ is orderly replaced at the position of one $\mathrm{R}$, and Co shifts slightly from 


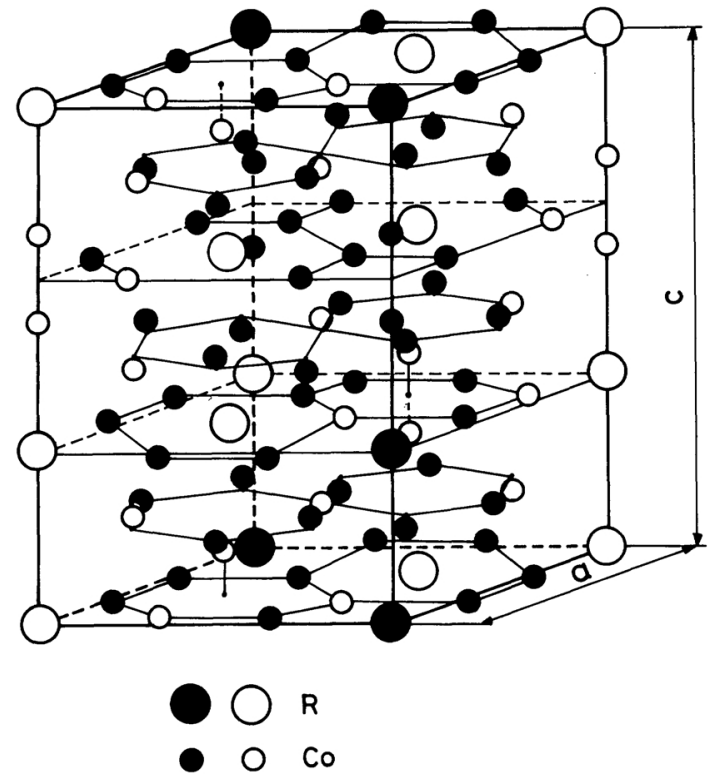

Fig. 12 Unit cell of the structure of the $\mathrm{R}_{2} \mathrm{Co}_{17}$ type. White spheres show particles observed in Fig. 10.

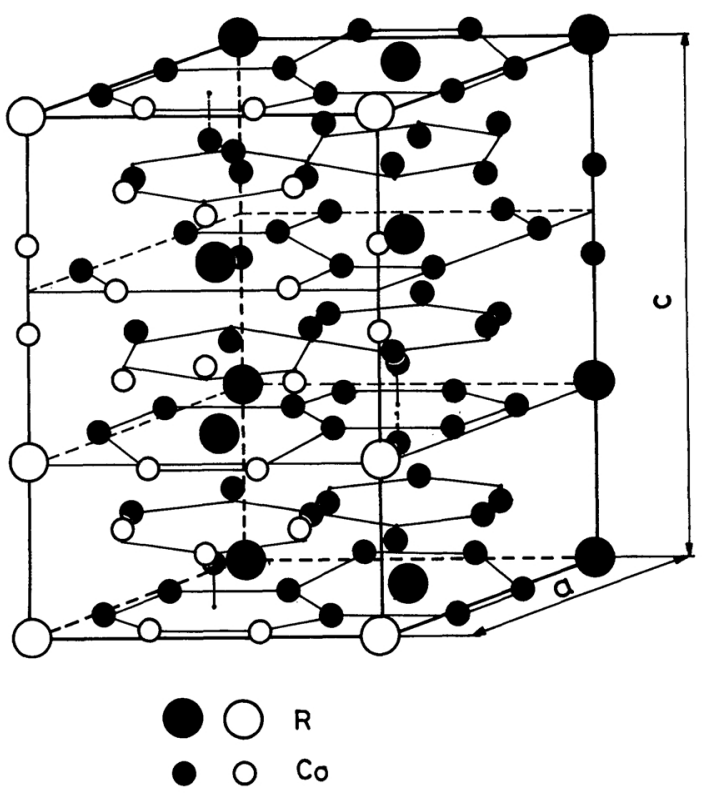

Fig. 13 Unit cell of the structure of the $\mathrm{R}_{2} \mathrm{Co}_{17}$ type. White spheres show particles observed in Fig. 11.

the Co position in the structure of the $\mathrm{RCo}_{5}$ type. This axial ratio $c / a$ is about 1.5 , being very close to the axial ratio in the real intermetallic compounds with the structure of the $\mathrm{R}_{2} \mathrm{Co}_{17}$ type.

Such intermetallic compounds have now become available as hard magnetic materials $^{(19)(20)}$. The internal structures and their changes determine the properties of these materials and hence should be understood at atomic level, in order to improve materials. More fully observing the latexes will be desired to become a more useful method for understanding on an atomic scale the structures and their changes of the $\mathrm{RCo}_{5}$ and the $\mathrm{R}_{2} \mathrm{Co}_{17}$ types of favorable intermetallic compounds.

\section{Conclusions}

The polystyrene latexes with the particles of diameters 250 and $500 \mathrm{~nm}$ were observed under a metallurgical microscope.

The particles in the polystyrene latexes move thermally at the early stage, as if they were atoms in the liquid state or the amorphous state, and then form gradually the structures of the $\mathrm{RCo}_{5}$ and the $\mathrm{R}_{2} \mathrm{Co}_{17}$ types. Various lattice defects such as the diffuse interfaces between the two structures, dislocations, segregations of the large and the small particles around boundaries and point defects are threedimensionally observed with various morphologies.

\section{REFERENCES}

(1) S. Hachisu: Gendaikagaku, (1973), No. 10, 10 (in Japanese).

(2) S. Hachisu and K. Takano: Bull. Japan Inst. Metals, 15 (1976), 455 (in Japanese).

(3) S. Hachisu: Hyomen, 14 (1976), No. 1, 15 (in Japanese).

(4) K. Takano and S. Hachisu: Butsuri, 31 (1976), 135 (in Japanese).

(5) N. Ise: Kagaku, 35 (1980), 293 (in Japanese).

(6) F. Kitahara and K. Furusawa: Bunsan Nyukakei no Kagaku, Kogakutosho, (1980), p. 36 (in Japanese).

(7) J. W. Vanderhoff: Pure \& Appl. Chem., 52 (1980), 1263.

(8) R. K. Kalia and P. Vashishta: J. Phys. C: Solid State Phys., 14 (1981), L643.

(9) T. Ohtsuki, A. Kishimoto, S. Mitaku and K. Okano: Japan. J. Appl. Phys., 20 (1981), 509.

(10) K. Okano, S. Mitaku and T. Ohtsuki: Oyo Buturi, 50 (1981), 270 (in Japanese).

(11) S. Hachisu and S. Yoshimura: Nature, 283 (1980), 188.

(12) S. Hachisu and S. Yoshimura: Oyo Buturi, 49 (1980), 1137 (in Japanese).

(13) M. Hasaka, H. Nakashima and K. Oki: J. Japan 
Inst. Metals, 45 (1984), 347 (in Japanese).

(14) M. Hasaka, H. Nakashima and K. Oki: Trans. Japan Inst. Metals, 25 (1984), 65.

(15) Y. Ishida, S. Okamoto and S. Hachisu: J. Japan Inst. Metals, 41 (1977), 1180 (in Japanese).

(16) Y. Ishida: Metal Physics Seminor, 3 (1978), No. 2, 63 (in Japanese).

(17) Y. Ishida, S. Okamoto and S. Hachisu: Acta Met., 26 (1978), 651.

(18) Y. Ishida and H. Ichinose: Bull. Japan Inst. Metals, 20 (1981), 487 (in Japanese).

(19) H. Kaneko: Bull. Japan Inst. Metals, 15 (1976),
109 (in Japanese).

(20) M. Hamano: Bull. Japan Inst. Metals, 16 (1977), 79 (in Japanese).

(21) I. Pfeiffer: Z. Metallk., 73 (1982), 174.

(22) R. Kiriyama and H. Kiriyama: Kozomukikagaku I, Kyoritsushuppan, (1972), p. 238 (in Japanese).

(23) T. Nakamichi: Hikagakuryoronteki Kinzokukankagobutsu, Ed. by Japan Inst. Metals, Maruzen, (1975), p. 296 (in Japanese).

(24) R. K. Mishra and G. Thomas: Int. Workshop Rare Earth Cobalt Perm. Magnets Their Appl. 4th, (1979), 301. 